\title{
Evaluation of the Influence of a Rail Vehicle Running with Wheel-flat on the Railway Track
}

\author{
Ján Dižo $^{1^{*}}$, Miroslav Blatnický1 ${ }^{1}$ Stasys Steišūnas ${ }^{2}$ and Gediminas Vaičiūnas ${ }^{2}$ \\ ${ }^{1}$ University of Žilina, Faculty of Mechanical Engineering, Department of Transport and Handling \\ Machines, Univerzitná 8215/1, 01026 Žilina, Slovak Republic; Email: jan.dizo@fstroj.uniza.sk, \\ miroslav.blatnicky@fstroj.uniza.sk \\ ${ }^{2}$ Vilnius Gediminas Technical University, Faculty of Transport Engineering, Department of Mobile \\ Machinery and Railway Transport, J. Basanavičiaus g. 28, LT-03224, Vilnius, Lithuania; Email: \\ stasys.steisunas@vgtu.lt,gediminas.vaiciunas@vgtu.lt
}

*Corresponding Author: jan.dizo@fstroj.uniza.sk

\begin{abstract}
The railway transport network is currently in a quite big expansion. Therefore, railway tracks are modernized and the attention is given also on the technical state of rail vehicles, which operate on them. However, it may happen that the wheel surface is damaged. One of the most common reasons of wheel damage is too much braking, which results to the wheel-flat formation. This article is focused on the evaluation of the influence of a rail vehicle running on the railway track, which a wheel is damaged by the wheel-flat. Investigation of these negative effects was performed by means of simulation computations. As evaluating parameters, values of the wheel force in the contact of the rail and wheel with a flat where observed.
\end{abstract}

Keywords: Rail vehicle, simulation computations, wheel-flat, vertical wheel forces

\section{Introduction}

Nowadays, the rail transport is increasingly used, mainly for the transport of large number of passengers or big amount of goods on longer distances [1]. However, this trend means also increasing number of transport means running on railway tracks and therefore even greater possibility of eventual failures [2]. Despite the fact that rail vehicles technical state is currently quite strict monitored and inspected [3,4], a damage of wheels surfaces can occur.

There are several types of wheel damages as a results of surface and subsurface fatigue, heat (thermal fatigue), further also indentations, wear, etc. Except for these types of wheel defects we know also the wheel-flat defect. This type of railway wheel profile damage is formed by a locked wheel sliding on a rail during braking [5], while a part of the wheel becomes flattened. This defects causes high impact loads, which may results on one hand in cracking and noise and on the other hand in discomfort. Operation of a rail vehicle with such a damaged wheel leads to serious defects 
of rail vehicles and tracks and increases the risk of train traffic safety. Due to these reasons we effort to detect and evaluate negative effects of rail vehicle running with wheel defects on a track [6].

\section{Computational Modelling of a Rail Vehicle with the Wheel-flat}

Rail vehicles properties as a mechanical system can be designed, studied, evaluated and verified by means of experimental methods and measurements in real operation or in laboratories conditions using special equipment [7-9]. Another approach based on numerical methods allow to create virtual models of rail vehicle subsystems $[10,11]$ or whole rail vehicle and even rail units and trains $[12,13]$ in specialized software, which are able to analyze running properties of them sufficiently accurate and fairly quickly.

In this work, we have focused on the evaluation of the influence of a rail vehicle running with the damaged wheel on a railway track using numerical calculation. In our research we have used the Simpack multibody software. In this computer tool several types of damaged wheels including the wheel flat is possible to model.

The wheel-flat is usually modeled as a circumference chord of the length $L$. The depth of a flat we denote $h$ (Fig. 1). Wheel-flat edges are singular points, where the curvature changes from the nominal wheel radius from $R$ to $\infty$. If we consider the wheel geometry in accordance with Fig. 1, the length of the flat related to the wheel radius and the flat length is [14]:

$$
L=2 \cdot \sqrt{2 \cdot R \cdot h-h^{2}} \cong \sqrt{8 \cdot R \cdot h} .
$$

Wheel untrueness causes force changes in the wheel/rail contact and increase requirements for the wheel/contact calculation $[15,16]$. As we can see, the wheel-flat make the wheel radius no longer constant during calculation, but it varies in a flat location with the angle $\varphi$ form the minimum value $R-h$ up to the value $R$.

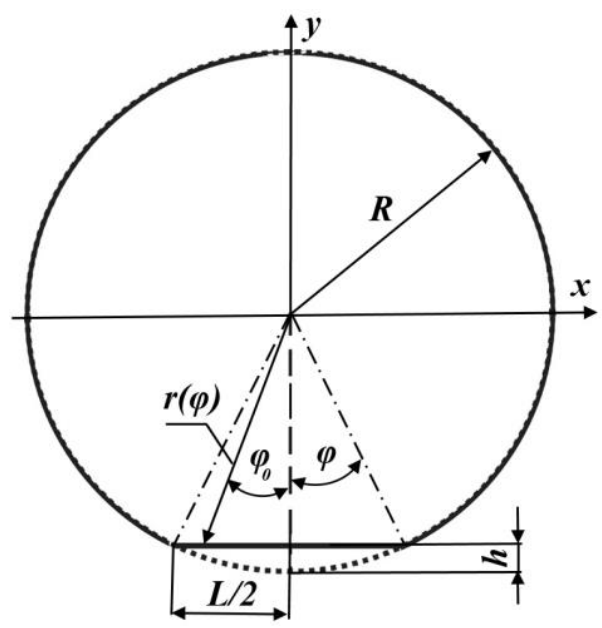

Fig. 1 Geometry of the wheel-flat. Source: [14] 
In our model the wheel-flat is described pointwise by means of a function. The angle $\varphi$ is its independent value and it is defined in the interval $\langle 0,2 \cdot \pi\rangle$. The radius derivation $r(\varphi)$ is the dependent coordinate.

As an investigated rail vehicle the coach equipped by two two-axle bogies was chosen. The suspension of this wagon is ensured by a primary and a secondary suspension. The virtual model of a coach forms a multibody system and from the mathematical point of view it is described by the known system of the equations of motion [17]. Its general matrix form is:

$$
\boldsymbol{M} \cdot \ddot{\boldsymbol{x}}+\boldsymbol{B} \cdot \dot{\boldsymbol{x}}+\boldsymbol{K} \cdot \boldsymbol{x}=\boldsymbol{Q},
$$

where $\boldsymbol{M}, \boldsymbol{B}$ and $\boldsymbol{K}$ are mass, damping and stiffness matrices, respectively, $\boldsymbol{x}$ is the system of degrees of freedom displacements and $\dot{\boldsymbol{x}}$ and $\ddot{\boldsymbol{x}}$ are their appertained derivations expressing velocities and accelerations, respectively. The right-hand side of the equation (1) represents the vector of loads. It is given by the contact forces vector $\boldsymbol{F}_{C}$ and the external forces vectors $\boldsymbol{F}_{E}$ according to following formula:

$$
\boldsymbol{Q}=\boldsymbol{F}_{C}+\boldsymbol{F}_{E} .
$$

Contact force terms and external forces result from track profiles, wheels and track irregularities, etc. [18].

\section{Results of Simulation Computations}

Simulations of a coach running were conducted on a straight track model. Into the track model we have implemented also track irregularities.

By reason that we have wanted to investigate influences of the rail vehicle operation with a damaged wheel in our specified operation conditions, we have chosen range of speeds from $40 \mathrm{~km} \cdot \mathrm{h}^{-1}$ to $160 \mathrm{~km} \cdot \mathrm{h}^{-1}$. Analyses were recorded at corresponding sampling rates depending on speeds. Moreover we have evaluated also various damage ranges by defining the typical dimensions of the wheel-flat, i.e. the depth $h$ and the resultant length $L$. The depth of the flat was considered from $1 \mathrm{~mm}$ to $2.5 \mathrm{~mm}$.

As the track load criteria waveforms of the vertical wheel force in a contact of the wheel with flat and rail were observed. We have recorded data for various speeds and flat dimensions in time. It means we have relatively large number of simulations of a rail vehicle running. Therefore, for the presentation of results we have chosen outputs in such a form, which visual illustrates monitored quantities in partial range. Furthermore, we have also statistically processed the vertical wheel forces outputs and we have created a cumulative graph to show results of them for all investigated speeds and flat dimensions. 
Fig. 2 shows cumulative graph of waveforms of statistically unprocessed outputs of vertical wheel forces calculated in the contact of wheel with the flat and the rail. There are shown results for the coach speed of running of $80 \mathrm{~km} \cdot \mathrm{h}^{-1}$, for four depth of the flat $h(1 \mathrm{~mm}, 1.5 \mathrm{~mm}, 2 \mathrm{~mm}$ and $2.5 \mathrm{~mm}$ ) in relatively short time interval of $1.5 \mathrm{~s}$.

From this figure we can see, that the flat on a wheel causes significant additional load on a track. These impacts overload all elements of permanent way such rails, sleepers and ballast.

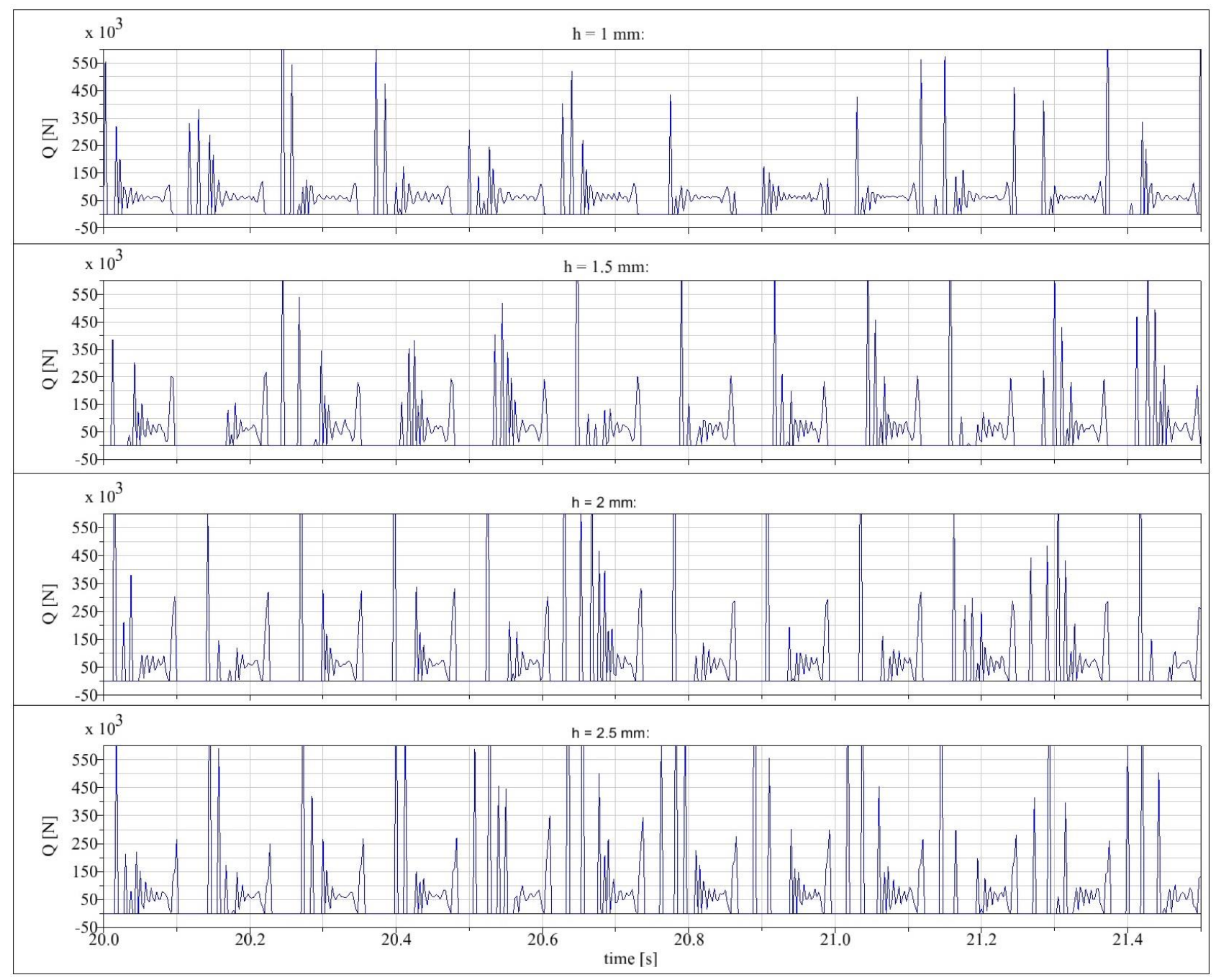

Fig. 2 Unprocessed signal of outputs of forces between a wheel with flat and rail for speed of $80 \mathrm{~km} \cdot \mathrm{h}^{-1}$, top down: $h=1 \mathrm{~mm}, 1.5 \mathrm{~mm}, 2 \mathrm{~mm}$ and $2.5 \mathrm{~mm}$. Source: authors

In case of rails, there is the damage of their profiles, which leads to significant changes in the wheel/rail contact. With this phenomenon the safety against derailment expressed as the lateral $Y$ and vertical wheel forces $Q$ ratio (Y/Q) [19] is closely related. As we can see (Fig. 2), during a wheel rotation values of the vertical wheel forces are periodically changing and when they are small, the $Y / Q$ ration reach high values. It follows, that operation of a rail vehicle with damaged wheel is not safety. 
Sleepers and ballast are other loaded elements of a track subjected to the increased load level. It leads to more often interventions of track maintenance.

By statistical processing of results of vertical wheel forces we have obtained effective vertical wheel forces $Q_{e f}$ which load a track. These outputs are entered into the cumulative graph, which shows investigated results for all range of running conditions (Fig. 3).

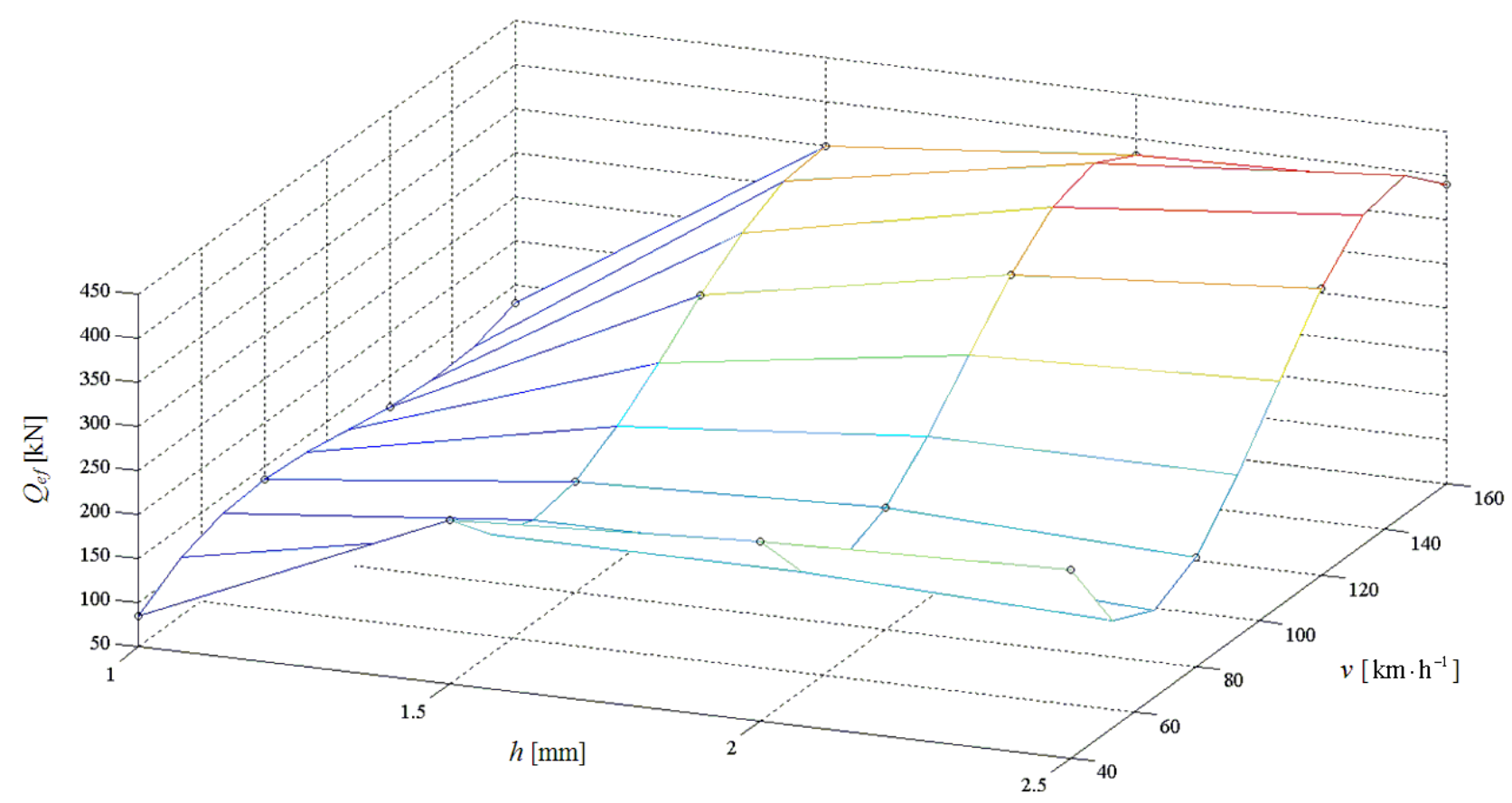

Fig. 3 Cumulative graph with outputs quantities. Source: authors

Based on these results we can analyze running properties of the rail vehicle with the wheel-flat during operation. Generally we observe, the greatest load of the track is in case of coach running with the deepest flat $(h=2.5 \mathrm{~mm})$ running at the highest speed $\left(v=160 \mathrm{~km} \cdot \mathrm{h}^{-1}\right)$. But, the dependence of the vertical wheel force on flat depth and on speed is not linear.

As if it would be assumed, values of the vertical wheel force increase with the depth of flat direct proportionally. More interesting situation is in case of the comparison of the dependence of vertical wheel forces on the running speed of the coach. Notice that values $Q_{e f}[\mathrm{kN}]$ increase with the speed in the interval approx. from $90 \mathrm{~km} \cdot \mathrm{h}^{-1}$ to $150 \mathrm{~km} \cdot \mathrm{h}^{-1}$. But, at smaller speeds, approx. from $50 \mathrm{~km} \cdot \mathrm{h}^{-1}$ to $90 \mathrm{~km} \cdot \mathrm{h}^{-1}$, they are even smaller than at the speed of $40 \mathrm{~km} \cdot \mathrm{h}^{-1}$.

This is the important finding, which proves the interesting phenomenon investigated and described in several works, e.g. [20]. They deal with the fact, that there is some range of speeds, in which the negative effects rail vehicle running with the wheel-flat utter least, and for speeds greater and even smaller than it negative effects are worse.

As in our findings based on simulation computations values of vertical wheel forces of a rail vehicle with the wheel-flat reach great peaks (Fig. 2), which could cause in reality enormous load of 
the track, future research in this field will be focused on the improvement of a computer model in such way to consider the realistic relatively quick wear of edges of the newly formed flat [21]. Further it will be needed to take into account also other irregularities of wheels. After this manner modified model will serve for simulations its running of a track whereby it is intended to compare results from simulations with experimental data.

\section{Conclusion}

This article dealt with the modeling, simulation and investigation running properties of a rail vehicle which has a damaged wheel by the flat. The wheel-flat is one of the most often defect of a wheel profile. It can cause various problems during the operation of such a rail vehicle. In addition to the impaired running ability of it, a track is subjected significantly increased additional load, which damages profiles of rails and rail profile. This implies the deteriorated safety of railway operation. Therefore there is necessary such situation investigate and predict in advance. In this work the message, procedure and same results were presented.

\section{Acknowledgment}

This work was supported by the Cultural and Educational Grant Agency of the Ministry of Education of the Slovak Republic in the project No. KEGA 007ŽU-4/2017: Modernization of the Vehicle and engines study programs.

\section{References}

[1] Mašek, J., Kendra, M., Milinkovič, S., Veskovič, S. \& Barta, D. (2015). Proposal and application of methodology of revitalisation of regional railway track in Slovakia and Serbia. Part 1: Theoretical approach and proposal of methodology for revitalisation of regional railways. Transport Problems, 2015, 85-95.

[2] Grenčík, J., Poprocký, R., Galliková, J. \& Volna, P. (2018). Use of risk assessment methods in maintenance for more reliable rolling stock operation. MATEC Web of Conferences, 157, DOI: $10.1051 /$ matecconf/201815704002.

[3] Melnik, R. \& Sowinski, B. (2013). Application of the rail vehicle's monitoring system in the process of suspension condition assessment. Komunikacie, 15(4), 3-8.

[4] Chudzikiewicz, A., Bogacz, R. \& Kostrzewski, M. (2014). Using acceleration signals recorded on a railway vehicle wheelsets for rail track condition monitoring. In $7^{\text {th }}$ European Workshop on Structural Health Monitoring: EWSHM $2014-2^{\text {nd }}$ European Conference of the 
Prognostics and Health Management (PHM) Society2014, 8-11 July 2014 (167-174). Nantes, France.

[5] Suchánek, A., Harušinec, J., Loulová, M. \& Strážovec, P. (2018). Analysis of the distribution of temperature fields in the braked railway wheel. MATEC Web of Conference, 157. DOI: 10.1015/2fmatecconf/2f2018.15702048.

[6] Ližbetin, J., Vejs, P., Stopka, O. \& Cempírek, V. (2016). The significance of dynamic detection of the railway vehicles weight. Nase More, 63(3), 156-160.

[7] Gerlici, J., Lack, T. \& Harusinec, J. (2014). Realistic simulation of railway operation on the RAILBCOT test stand. Applied Mechanics and Materials, 486, 387-395. DOI: 10.4028/www.scientific.net/AMM.486.387.

[8] Nangolo, N.F. \& Klimenda, F. (2014). System identification for underdamped mechanical systems. In EAN 2014: 52 ${ }^{\text {nd }}$ International Conference on Experimental Stress Analysis, 2-5 June 2014, Marianske Lazne, Czech Republic.

[9] Hren, I., Hejma, P., Michna, S., Svoboda, M. \& Soukup, J. (2018). Analysis of torque cam mechanism. MATEC Web of Conference, 157, DOI: 10.1051/matecconf/201815706004.

[10] Št'astniak, P., Smetanka, L. \& Moravčík, M. (2017). Development of modern railway bogie for broad track gauge - bogie frame assessment. Manufacturing Technology, 17(2), 250-256.

[11] Hauser, V., Nozhenko, O., Kravchenko, K., Loulova, M., Gerlici, J. \& Lack, T. (2017). Impact of three boxes bogie to tram behaviour when passing curved track. Procedia Engineering, 192, 295-300. DOI: 10.1016/j.proeng.2017.06.051.

[12] Kostrzewski, M. \& Melnik, R. (2017). Numerical dynamics study of a rail vehicle with differential gears. Procedia Engineering, 192, 439-444. DOI: 10.1016/j.proeng.2017.06.076.

[13] Bogdevičius, M. \& Žygiene, R. (2017). Research of System Vehicle-track when Wheel is Scaled. Procedia Engineering, 187, 599-603. DOI: 10.1016/2fj.proeng.2017.04.419.

[14] Brizuela, J., Fritsch, C. \& Ibanez, A. (2011). Railway wheel-flat detection and measurement by ultrasound. Transportation Research Part C, 19, 978-984. DOI: 10.1016/j.trc.2011.04.004.

[15] Lack, T. \& Gerlici, J. (2014). A modified strip method to speed up the calculation of normal stress between wheel and rail. Applied Mechanics and Materials, 486, 359-370. DOI: 10.4028/2fwww.scientific.net/2fAMM.486.359. 
[16] Lack, T. \& Gerlici, J. (2015): The FASTSIM method modification to speed up the calculation of tangencial contact stressess between wheel and rail. Manufacturing Technology, 13(4), 486-492.

[17] Mazilu, T. (2007). A dynamic model for the impact between the wheel flat and rail. UPB Scientific Bulletin, Series D: Mechanical Engineering, 69(2), 45-58.

[18] Bogdevičius, M., Žygiene, R., Dailydka, S., Bartulis, V., Skrickij, V. \& Pukalskas, S. (2015). The dynamic behaviour of a wheel flat of a railway vehicle and rail irregularities. Transport, 30(2), 217-232. DOI: 10.3846/2f16484142.2015.1051108.

[19] UIC CODE 518. (2009). Testing and approval of railway vehicles from the point of view of their dynamic behaviour - Safety - Track fatigue - Running behaviour. September 2009. Paris, France.

[20] Pawelczyk, M., Piotr, L. \& Podsiadlo, R. (2015). Simulation study of the 4-axle wagon damaging impact on the track caused by some deformations of the wheel. In Current Problems in Rail Vehicles - PRORAIL 2015: $22^{\text {nd }}$ International Conference, 16-18 September 2015 (115-124), Žilina, Slovakia.

[21] Steenbergen, M.J.M.M. (2008). Wheel-rail interaction at short-wave irregularities. Delft: Wöhrmann Print Service, Zutphen. 